\title{
Energy Efficient Snubber Networks
}

\author{
M. Darwish \\ Department of Electronic and \\ Computer Engineering. \\ Brunel University \\ London, UK \\ mohamed.darwish@Brunel.ac.uk
}

\author{
CC Marouchos \\ Department of Electrical \\ Engineering, \\ Cyprus University of Technology \\ Limassol, Cyprus \\ christos.marouchos@cut.ac.cy
}

\author{
Al Janbey \\ London College UCK, \\ Division of Electrical and \\ Electronic Engineering, \\ London, U.K. \\ a.janbey@lcuck.ac.uk
}

\author{
H. Amreiz \\ London College UCK, \\ Division of Electrical and \\ Electronic Engineering, \\ London, U.K. \\ h.amreiz@lcuck.uk
}

\begin{abstract}
- conventional snubber networks which are used to remove the stress from semiconductor devices during turning-on and turning-off are used to shape the switching locus to keep it within the Safe Operating Area (SOA) and to reduce the turn-on and turn-off switching losses in the switching devices. Usually a large snubber inductance or capacitance is found to be effective in reducing the dissipation in a resistor. It would be more efficient if, after extracting the switching energy from the semiconductor device, to feed this energy somewhere useful instead of dissipating it as a heat. By doing so, the overall efficiency of the converter would be improved. This is the aim of energy-efficient snubber circuits which is presented in this paper.
\end{abstract}

Index Terms - snubber circuits, semiconductor devices

\section{INTRODUCTION}

Even when equipped with proper drive circuitry, real semiconductor switches have a non-zero switching time. During the turn-on and turn-off times, the switches deal with simultaneous voltage and current (current rising and voltage falling during the turn-on and current falling and voltage rising during the turn-off). This results on switching loss in the semiconductor. The switch current and voltage waveforms depend on the load circuit as well as on the characteristics of the switch. One way to remove the stress from the switch during the turn-on and turn-off times is to force either the voltage or the current to be zero during the turn-on or turn-off times. This can be done by adding passive components (L-R) in the turn-on and (C-R) in the turn-off. Both the turn-on inductor and turn-off capacitor divert the energy from the switch during the turn-on and turn-off times and force this energy to be dissipated as a heat a resistor. The L-R and LC circuits are called dissipative snubber networks. The word 'dissipative' is used because they do not reduce the switching losses but instead of that, they divert the losses from the delicate/expensive semiconductor switches to a rugged/cheap resistor. In this paper a brief review of the dissipative snubber networks are presented followed by some proposed energy- efficient snubber networks where no resistor is used and the sored energy on the turn-on inductor and turn-off capacitor are recovered and fed back to the source. By doing so, not only the semiconductor switches will be stress-free but also the overall efficiency of the converter, where the switch is used, will increase $[1,2]$.

\section{THE SWITCH CHARACTERISTIS}

Fig. 1 shows the current and voltage waveforms during the turn-on and turn-off times. If the turn-on and turn-off times are equal, then the relationship between the current through the switch and the voltage across the switch will be linear (as illustrated in Fig. 1. However, if the turn-on time is larger than the turn-off time (which is usually the case), then the $\mathrm{i}-\mathrm{v}$ relationship can take a different shape as the one shown in Fig. 2.

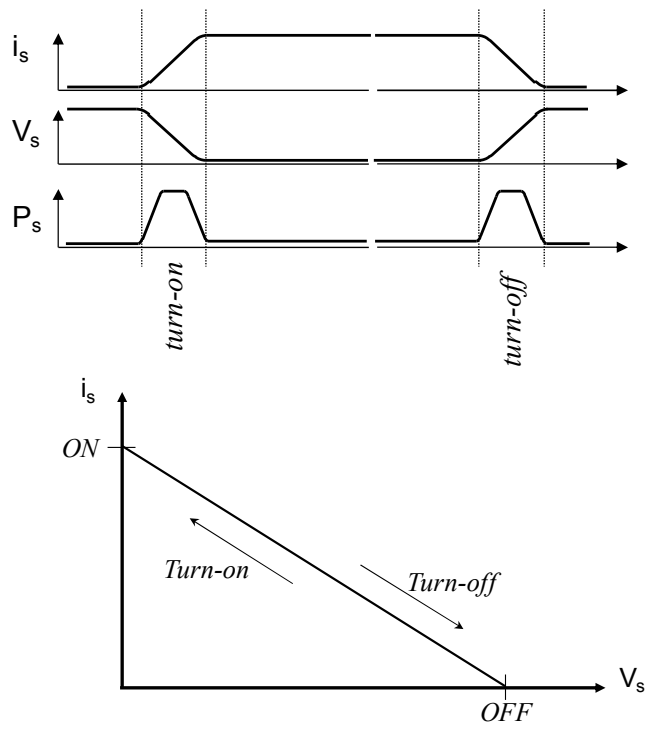

Fig. 1: Switching characteristics for equal turn-on / turn-off times 

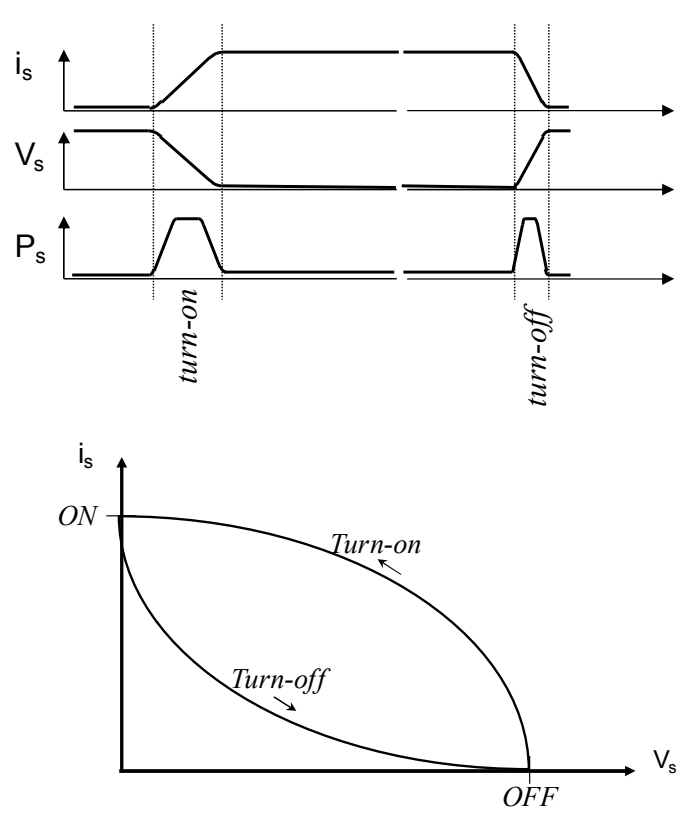

Fig. 2: Switching characteristics for turn-on $>$ turn-off

The whole idea of the snubber network is either to force the voltage across the switch to go to zero (or near zero) during the turn-on or to divert the switch current during the turn-off. By doing so the power dissipated in the switch will be zero (or close to zero as illustrated in Fig. 3.
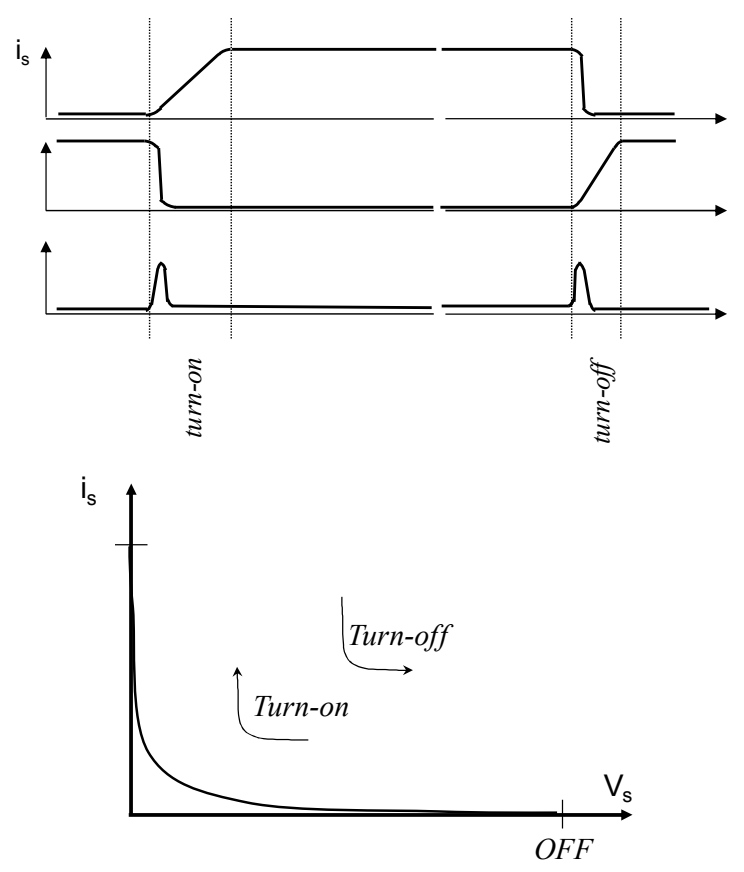

Fig. 3: Switching characteristics when turn-on $>$ turn-off

The following sections show how that can be achieved with turn-on and turn-off snubber networks.

\section{Dissipative TURN-ON SNUBBER NeTWORK}

The turn-on snubber network is simply a circuit connected in series with the semiconductor switch. The turn-on snubber consists of an inductor ' $L$ ', a resistor ' $R$ ' and a diode ' $D$ ' as shown in Fig. 4. The basic idea is to select an appropriate value of an inductor so that during the turn-on time the voltage developed across ' $\mathrm{L}$ ' equals the supply voltage ' $\mathrm{V}$ ' and hence the voltage across the switch ' $\mathrm{V}_{\mathrm{s}}$ ' becomes zero (or near zero) during the turn-on time.

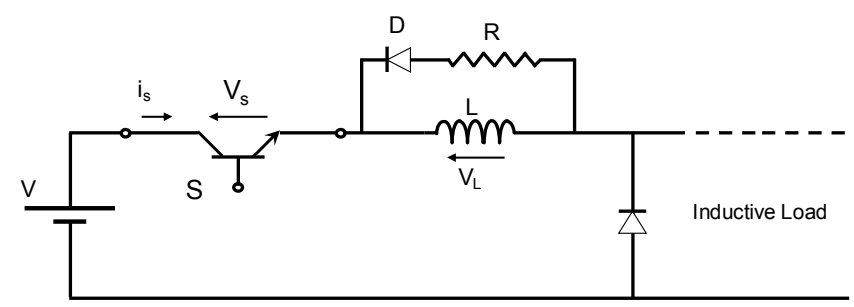

Fig. 3: Dissipative turn-on snubber network

Initially, no current flows in ' $\mathrm{S}$ ' and the small snubber inductance ' $L$ '. As the current through ' $S$ ' rises during turnon, a voltage $\mathrm{V}_{\mathrm{L}}=\mathrm{L} \mathrm{di}_{\mathrm{s}} / \mathrm{d}_{\mathrm{t}}$ is developed across $\mathrm{L}$.

Assuming that ' $\mathrm{i}_{\mathrm{s}}$ ' increases linearly with ' $\mathrm{t}$ ', then the voltage across the inductor during the turn-on time: $\mathrm{V}_{\mathrm{L}}=\mathrm{L} \mathrm{I} / \mathrm{t}_{\mathrm{r}}$.

If we choose $\mathrm{L}$ so that $\mathrm{V}_{\mathrm{L}}=\mathrm{V}$, there will be zero voltage developed across ' $\mathrm{S}$ ' during $\mathrm{t}_{\mathrm{r}}$, giving zero turn-on loss in the switching device. Note that there is energy of $1 / 2 \mathrm{LI}^{2}$ is stored in ' $L$ ' and must be removed (during $t_{\text {off }}$ time) so that the snubber is reset by the start of the next cycle. Resistor ' $R$ ' and a diode ' $D$ ' are used to dissipated this energy as a heat. The value of ' $R$ ' is not critical, but two factors restrict it: The time-constant $\mathrm{L} / \mathrm{R}$ must be short enough so that the current can decay sufficiently during toff. Also, immediately after ' $\mathrm{S}$ ' has opened it sees a voltage ' $\mathrm{V}+\mathrm{IR}$ ' across it. The voltage rating of ' $\mathrm{S}$ ' must therefore be increased to withstand such voltage.

The power dissipated in ' $\mathrm{S}$ ' during $\mathrm{t}_{\mathrm{on}}$ is ideally zero. The power dissipated in ' $R$ ' is simply the stored energy multiplied by the switching frequency $(1 / T)$.

$\mathrm{P}_{\mathrm{R}}=\mathrm{LI}^{2} /(2 \mathrm{~T}) \quad$ (Note that $\mathrm{P}_{\mathrm{R}}$ is independent of 'R').

If ' $\mathrm{L}$ ' is smaller than its optimum value, some power will be dissipated in ' $\mathrm{S}$ ' but correspondingly less will be dissipated in ' $R$ '. The total loss $P_{s}($ on $)+P_{R}$ remains the same.

If ' $\mathrm{L}$ ' is larger than its optimum value, the power dissipated in ' $S$ ' stays at zero while the dissipation in ' $R$ ' increases as shown in Fig. 4.

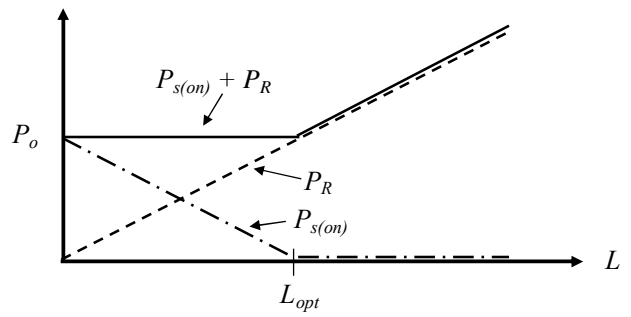

Fig. 4: Determining optimum value of ' $L$ ' 


\section{DISSIPATIVE TURN-OFF SNUBBER NETWORK}

The turn-off snubber network is simply a circuit connected in parallel with the semiconductor switch as shown in Fig. 5 in order to divert the current from the switch during the turn-off time. Initially current ' $\mathrm{I}$ ' is flowing in ' $\mathrm{S}$ ' and the small snubber capacitance ' $\mathrm{C}$ ' is uncharged. As the current through ' $\mathrm{S}$ ' decreases, ' $\mathrm{C}$ ' and $\mathrm{D}$ provide an alternative path for the balance of I, and the free-wheel inductive load diode remains reverse-biased.

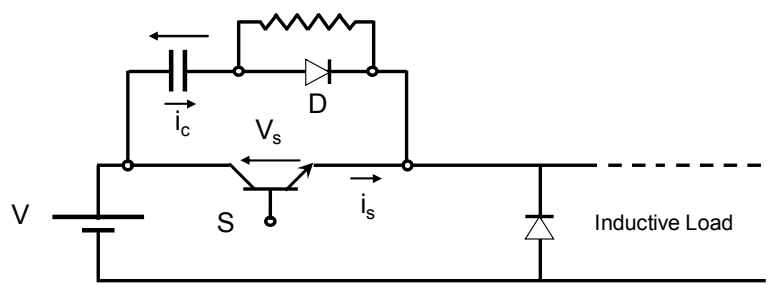

Fig. 5: Dissipative turn-off snubber network

Assuming that ' $i_{\mathrm{s}}$ ' falls linearly during $\mathrm{t}_{\mathrm{f}}$ then:

$i_{s}(t)=I\left(1-\frac{t}{t_{f}}\right)$

Where the time origin has been taken at the start of turn-off. The current flowing into ' $\mathrm{C}$ ' therefore increases linearly according to:

$i_{c}=\frac{I t}{t_{f}}$

Putting this into the capacitance equation:

$i=C \frac{d v}{d t}$

The energy dissipated in S during turn-off:

$W=\int_{0}^{t_{f}} \frac{I t^{2}}{2 C t_{f}} I\left(1-\frac{t}{t_{f}}\right) d t=\frac{I^{2} t_{f}^{2}}{24 C}$

If the switch current reaches zero before the capacitor fully charges, the capacitor voltage ' $\mathrm{V}_{\mathrm{c}}$ ' will be:

$V_{C}=\frac{I t_{f}}{2 C}$

Solving for the value of ' $\mathrm{C}$ ':

$C=\frac{I t_{f}}{2 V_{c}}$

The resistor is chosen such that the capacitor is discharged before the next time the transistor turns off. A time interval of three to five time constants is necessary for capacitor discharge. Assuming five time constants for complete discharge, the on time for the transistor:

$$
\begin{gathered}
t_{\text {on }} \geq 5 R C \\
R \geq \frac{t_{\text {on }}}{5 C}
\end{gathered}
$$

Now, there is an energy of $\left(1 / 2 \mathrm{CV}^{2}\right)$ stored in ' $\mathrm{C}$ ' and must be removed (during $t_{o n}$ ). The simplest way to do this is to add a diode ' $\mathrm{D}$ ' and a resistor ' $\mathrm{R}$ ' to the snubber. The voltage across ' $\mathrm{C}$ ' decays exponentially when the switch is closed. The value of $\mathrm{R}$ is not critical, but two factors restrict it:

The time constant $\mathrm{CR}$ must be short enough that $\mathrm{V}_{\mathrm{c}}$ can decay to a negligible value during ton. ( 3 to 5 time-constants will be sufficient). Immediately after the switch closes, it passes a current of $(\mathrm{I}+\mathrm{V} / \mathrm{R})$ greater than the snubbed current, I. The current rating of S must therefore be increased relative to the unsnubbed case.

Fig. 6 shows that there are two optimum values of ' $\mathrm{C}$ ' which can be selected. $\mathrm{C}_{\mathrm{opt}(1)}$ can be selected to minimise the total turn-off loss.

$\mathrm{C}_{\mathrm{opt}(1)}=0.22 \mathrm{I} \mathrm{t}_{\mathrm{f}} / \mathrm{V}$

$\mathrm{C}_{\text {opt(2) }}$ can also be selected to minimise the loss in ' $\mathrm{S}$ ' without increasing the total loss.

$\mathrm{C}_{\mathrm{opt}(2)}=0.91 \mathrm{I} \mathrm{t}_{\mathrm{f}} / \mathrm{V}$

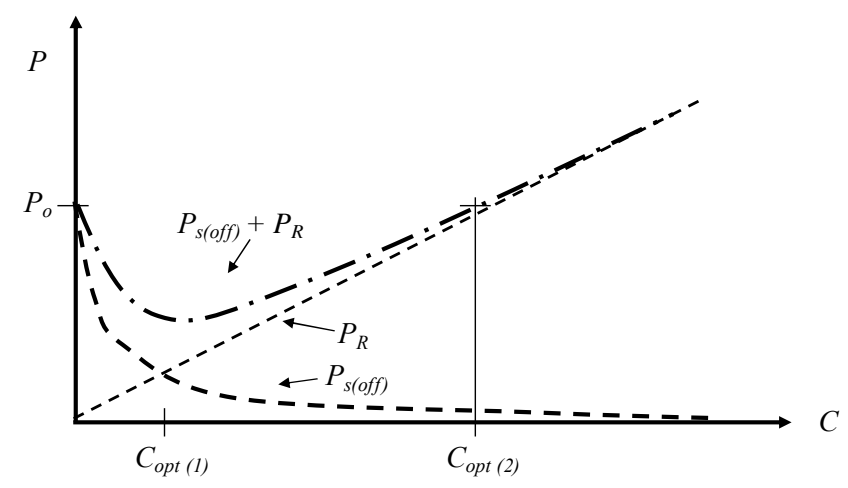

Fig. 6: Determining optimum values of ' $\mathrm{C}$ '

\section{COMBINED TURN-ON / TURN-OFF SNUBBER}

In this combined snubber network (Fig. 7), The values of ' $\mathrm{C}$ ' and ' $\mathrm{L}$ ' are determined as before. ' $\mathrm{R}$ ' must now be able to dissipate the sum of the turn-on loss $\left(\mathrm{P}_{\mathrm{R} \text {-on }}\right)$ and the turn-off loss ( $\left.\mathrm{P}_{\mathrm{R} \text {-off }}\right)$. The value of ' $\mathrm{R}$ ' must now be chosen with care as it forms part of both the turn-on and turn-off snubbers.

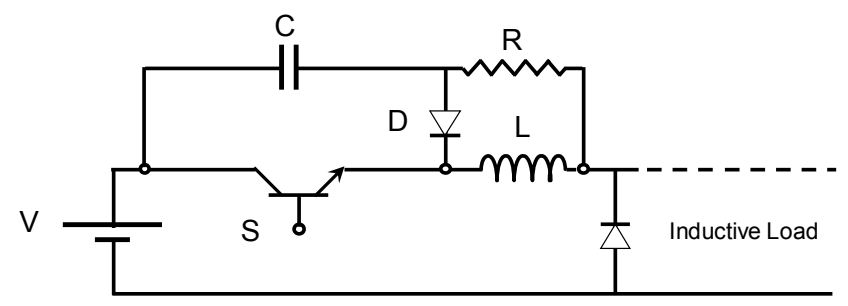

Fig. 7: Dissipative turn-off / turn-off snubber network 


\section{ENERGY-EFFICIENT TURN-ON SNUBBER NETWOK}

In the previous sections, dissipative snubber circuits are covered where a resistor ' $R$ ' is used to dissipate the energy which otherwise would have been dissipated in the switch. In this section a proposed circuits are used to divert this energy back to the source and hence increasing the overall efficiency of the converter circuit. Fig. 8 shows the principle of energyefficient turn-on snubber circuit. It works the same way as the dissipative turn-on snubber circuit as far as capturing the switch energy during the turn-on time and storing it in an inductor. However, this energy is transferred via a secondary mutual inductor and a diode to the main voltage source.

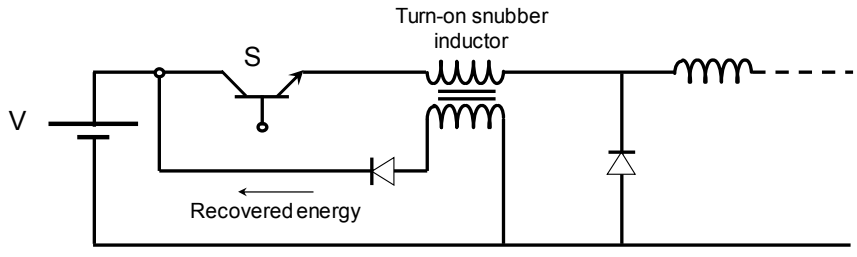

Fig. 8: Energy-efficient turn-on snubber network

The nonlinearity characteristics of inductor [3-5] are utilized in the energy-efficient snubber network. It is well known that the inductance of a linear inductor may be defined as $L=\Phi / i$ , where $\Phi$ is the magnetic flux and I is the current producing it. The stored energy in this case is $W=1 / 2 L i^{2}$. Now, what is the equivalent relation for a nonlinear inductor? $\Phi$ is no longer linearly related to $i$, so we can define a term 'incremental inductance' $L(i)$ as the rate of change of $\Phi$ with $i$.

$L(i)=d \Phi / d t$.

We can find the stored energy as:

$$
W(i)=\int_{0}^{i} \Phi(i) d i=\iint_{0}^{i} L(i) d i d i
$$

If the inductor saturates at $\left(I_{\text {sat }}, \Phi_{\text {sat }}\right)$, then the energy stored at a current $i>I_{\text {sat }}$ may be expressed as:

$$
\begin{aligned}
& W(i)=\int_{0}^{i} \Phi(i) d i=\int_{0}^{I_{\text {sat }}} \mathrm{L}_{0} i d i+\int_{I_{\text {sat }}}^{i} \Phi_{\text {sat }} d i \\
& W(i)=\frac{1}{2} L_{0} I_{\text {sat }}^{2}+L_{0} I_{\text {sat }}\left(i-I_{\text {sat }}\right)
\end{aligned}
$$

For large value of currents the stored energy is considerably less that that of linear inductance. This may be exploited in the snubber circuit. For example, consider $10 \mu \mathrm{H}$ snubber inductor carrying full load current of $5 \mathrm{~A}$. The stored energy in this case is $W=1 / 2 L i^{2}=125 \mu \mathrm{J}$. Now assume that a satisfactory snubbing can be obtained by using a non-linear inductor of $\mathrm{L}_{0}=10 \mu \mathrm{H}$ which saturates at $1 \mathrm{~A}$, the stored energy in that case using the equation in (3) will be $45 \mu \mathrm{J}$.
Thus the non-linear snubber circuit dissipates much less in comparison with linear snubber circuit.

\section{ENERGY-EFFICIENT TURN-OFF SNUBBER NETWOK}

The main idea is to use an auxiliary converter to feed the capacitor-stored energy back to the supply. Figure 9 shows the main idea of the energy-efficient turn-off snubber network.

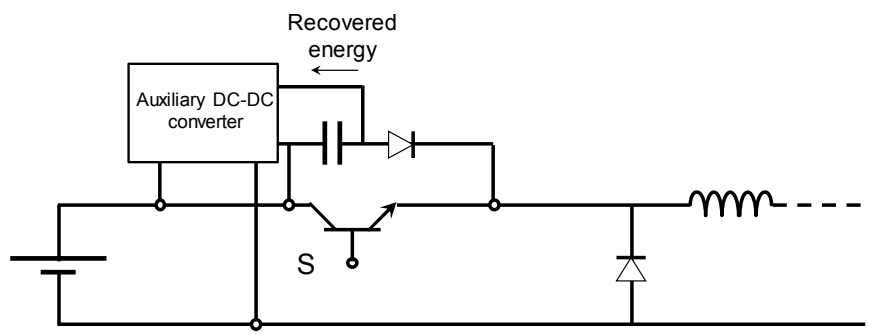

Fig. 9: Energy-efficient turn-off snubber network

The same way saturable inductor is utilized in energyefficient turn-on snubber circuit, a saturable capacitor (with a nonlinear dielectric) can also be utilized in energy-efficient turn-off snubber circuit. The stored energy can be expressed as:

$$
W(v)=\int_{0}^{v} q(v) d v=\iint_{0}^{v} C(v) d v d v
$$

Saturable snubber capacitors are at present only experimental devices. They are constructed with ceramic dielectrics [6], and the properties of the dielectric are probably quite variable.

\section{CONCLUSIONS}

Dissipative turn-on and turn-off snubber networks are incorporated in converter circuits to improve the reliability of the switching devices, but they may reduce the overall efficiency of the converter. With energyefficient snubber networks the loss in the snubbers may be reduced with a consequent increase in efficiency. If a saturable inductor is employed in a turn-on snubber, or a saturable capacitor in a turn-off snubber, the energy stored is less than when linear components are used.

\section{REFERENCES}

[1] Sat Mohanram, M. Darwish, CC Marouchos, "Power Switching Device Losses - Simulation and Non-Simulation Methods of Calculations", accepted in the IEEE University Power Engineering Conference (UPEC), September 2018.

[2] Sat Mohanram, M. Darwish, CC Marouchos, "Optimization and Simulation of RC Time Constants in Snubber Circuits", accepted in the IEEE University Power Engineering Conference (UPEC), September 2018Wilmar Martinez , Jun Imaoka , Masayoshi Yamamoto, "ZCS interleaved boost converter with saturable inductors for reverse- 
recovery reduction", IEEE 11th International Conference on Power Electronics and Drive Systems, 2015

[3] Nurhakimah M. Mukhtar, Dylan Dah-Chuan Lu, "A bidirectional flyback converter with cross-coupled non-dissipative snubber circuits", IEEE International Telecommunications Energy Conference (INTELEC), 2017.

[4] G. Tibola, E. Lemmen, J.L. Duarte, "Comparison between dissipative snubber and passive regenerative snubber cells as applied to isolated DCM SEPIC converters", 18th European Conference on Power Electronics and Applications (EPE'16 ECCE Europe), 2016.

[5] Kimihiro Nanamori , Imaoka Jun, Kenta Kono, Hideharu Tsukamoto , Masayoshi Yamamoto, "Verification of novel recovery-less boost converter with saturable inductor", International Conference on Renewable Energy Research and Applications (ICRERA), 2012.

[6] Jeffrey P. Calame, Morag Garven, Jacob Battat, David K. Abe ,David Lobas, "Broadband Dielectric Measurement Techniques and Systematic Dielectric Studies of Ceramic Composites for Vacuum Electronics Applications", IEEE International Conference on Plasma Science, 2005 